\title{
Evaluation of Synthesized Cross Linked Polyvinyl Alcohol as Potential Disintegrant
}

\author{
Ashok R. Patel* and Pradeep.R.Vavia \\ ${ }^{1}$ Centre for Novel Drug Delivery Systems, Department of Pharmaceutical Sciences and Technology, University Institute of \\ Chemical Technology, Matunga, Mumbai 400019, India
}

Received, September 21, 2009; Revised, March 19, 2010; Accepted, May 4, 2010; Published, May 10, 2010.

\begin{abstract}
Purpose: The present study deals with evaluation of crosslinked poly vinyl alcohol (PVA) as a potential disintegrant. Methods: Crosslinking of PVA was carried out using glutaraldehyde as a crosslinker, in presence of acidic conditions. The crosslinking reaction was optimized for a) polymer: crosslinker ratio; b) temperature requirement and c) reaction duration. Certain physical parameters of the disintegrant (including sedimentation volume, hydration capacity, specific surface area and bulk and tap density) were determined and compared to the known disintegrants. Characterization was carried out using FT-IR, DSC, XRD, SEM and Photo microscopy studies. The developed excipient was also studied for acute toxicity in rats and found to be safe for oral use. Results: Disintegration property of formed product was found to give better results. As compared to known disintegrant (Ac-Di-Sol). The disintegration mechanism of developed disintegrant was postulated based on results obtained from various physical evaluations. Hausner's ratio \& Carr's index value of 1.12 and 10.61 suggested excellent flowability. Wetting time and distintegration time of $21.90 \pm 0.1$ and $26.20 \pm$ 0.2 seconds was obtained at the disintegrant level of $5 \% \mathrm{w} / \mathrm{w}$. Conclusions: By changing the condition parameters of well known crosslinking reaction of PVA, we obtained a crosslinked product which had excellent disintegration activity, good flow and optimal tableting properties.
\end{abstract}

\section{INTRODUCTION}

In spite of extensive research in the field of modified release dosage forms, conventional tablets for oral ingestion remains the most widely accepted and developed formulations. To ensure high drug availability from such formulations relatively rapid disintegration is one of the pre-requisite. Currently, a class of disintegrants known as super disintegrants (represented by following three categories: crosslinked starch, crosslinked cellulose and crosslinked polyvinyl pyrollidone) are commonly used in formulation of tablets. Super disintegrants are unique in their own way as they are found to be effective at very low concentrations and yield disintegration time in seconds (1).

Polyvinyl alcohol (PVA) is a well known pharmaceutical excipient used for various purposes. The simplest and the most commonly employed crosslinking reaction involving chemical crosslinking of PVA with glutaraldehyde in presence of acidic conditions has been covered extensively in many research reports (2-3). It has been reported that chemical crosslinking of PVA can be used as an effective way of producing pharmaceutically safe and useful products (hydrogels, sludge, foam, sponge etc.) for drug delivery (4-7). However, till date none of the reports have been aimed at evaluating the possibility of using chemically crosslinked PVA as a disintegrating agent.

In this study, we have investigated, for the first time, the use of chemically crosslinked PVA as a disintegrating agent. We have found that changing the experimental conditions of well established chemical crosslinking reaction results in a material (hereinafter referred to as CLP), that can be compressed into a tablet, with or without the aid of a binder. The resulting tablet rapidly disintegrates in water, suggesting that CLP can be used as a disintegrating agent, especially in the design and development of fast-disintegrating tablets.

Corresponding Author: Dr. Ashok R. Patel, Email: ashok2510@gmail.com 
In this paper, we report the method of preparation of CLP and compare its disintegrating efficiency with known disintegrant i.e. Crosscarmellose (AcDi-Sol). Certain physical parameters of the disintegrant were evaluated to obtain an insight into its potential disintegrating efficiency. The study also includes characterization and toxicity evaluation of developed excipient. We have also attempted to postulate a mechanism by which CLP achieves its disintegrating action.

\section{MATERIALS AND METHODS}

\section{Materials}

Polyvinyl alcohol (PVA), (Mol. wt. 1, 25,000 and a degree of hydrolysis of 97.5-99.5 \% mole) was obtained from S.D fine-chem. Limited (Mumbai, India). Hydrochloric acid and glutaraldehyde (25\% w/v) were purchased from Merck Chemical Co. (India). Aceclofenac was kindly supplied by Aarti Drugs (Mumbai, India). Croscarmellose sodium (Ac-Di-Sol $\left.{ }^{\circledR}\right)$ and sodium starch glycolate (Primojel ${ }^{\circledR}$ ) were obtained from FMC BioPolymer (Philadelphia, PA) and DMV International (Veghel, Netherlands) respectively. Crospovidone (Polyplasdone $\left.{ }^{\circledR}\right)$ was purchased from Signet Chemicals (Mumbai, India) Dicalcium phosphate dihydrate (Emcompress $\left.{ }^{\circledR}\right)$ was obtained from JRS Pharma (Patterson, NY). Polyvinyl pyrollidone (Plasdone K-30®), Milled lactose (Pharmatose ${ }^{\circledR}$ $150 \mathrm{M}$ ), Sieved latose (Pharmatose ${ }^{\circledR} 50 \mathrm{M}$ ) and Magnesium stearate were obtained from DMV International (Veghel, Netherlands). Other reagents were analytical grade and double distilled water was used throughout the experiment. For animal studies, Milli-Q water purified using Millipore system (Molsheim, France) was used.

\section{Methods}

\section{Cross-linking procedure of PVA}

A chemical cross linking reaction utilizing glutaraldehyde was used in this study. Firstly, $5 \%$, $10 \%$ and $15 \% \mathrm{w} / \mathrm{v}$ PVA solutions were prepared by dissolving required amount of PVA in hot water at a temperature of $80-90{ }^{\circ} \mathrm{C}$. After cooling the solutions to room temperature, $100 \mathrm{ml}$ of each solution were used for proceeding steps. To above solutions different percentages of glutaraldehyde solution $(2.5-20 \% \mathrm{w} / \mathrm{v})$ was added as cross linking agent to obtain a polymer:crosslinker (PVA:GA) ratio ranging from $(1: 0.5$ to $1: 1.5 \% \mathrm{w} / \mathrm{w})$. The reactants were stirred continuously at $50-60^{\circ} \mathrm{C}$ for 20-40 mins on a magnetic stirrer (Remi Instrument, India). The above mixture was then poured into different volumes of acidic solution (concentrations varying from 0.1-0.4 N $\mathrm{HCl}$ ) followed by continuous agitation under constant heating on a magnetic stirrer until the precipitate was obtained. The reaction mixture was then cooled to room temperature and filtered. The white precipitate obtained was washed with water until the filtrate showed a near neutral $\mathrm{pH}$ and then subjected to overnight drying (yield $>85 \%$ ). The dried product was then passed through sieve no 60 and stored in a dessicator until further use.

\section{Characterization methods}

Surface morphology and particle size analysis The surface morphology of PVA and CLP particles was observed by scanning electron microscopy (Hitachi S-4000 microscope). The samples were loaded on aluminum stubs covered with a doublesided tape. They were then coated with a gold/palladium (60/40) mixture for $4 \mathrm{~min}$ in an Emitech K550 coater. Particle size analysis and specific surface area determination was carried out using Malvern Meta-sizer equipped with 2000 Hydro MU.

Fourier-transform infrared (FT-IR) spectroscopy Fourier transform infrared (FTIR) spectra of the samples were obtained in the range of 400 to 4000 $\mathrm{cm}^{-1}$ using a Jasco-FTIR spectrophotometer (Jasco, Essex, UK) by the $\mathrm{KBr}$ disc method. Pellets were prepared using a pressure of 14,000 pound for 2 minutes.

\section{Powder X-ray diffractometry}

The powder X-ray diffraction (XRD) measurements were conducted over a $10-40^{\circ} 2 \theta$ range on a Siemens Model D5000 diffractometer, equipped with monochromatic $\mathrm{Cu} \mathrm{K} \alpha\left(\alpha_{1}=1.54060 \mathrm{~A}^{\mathrm{o}}, \alpha_{2}=\right.$ $1.54438 \mathrm{~A}^{\circ}$ ) X-rays. The step width was $0.020^{\circ} 2$ $\theta /$ min with a time constant of $0.5 \mathrm{~s}$.

\section{Differential Scanning Calorimetry}

The samples were subjected to DSC studies using (Perkin Elmer pyris 4 series). Samples were sealed 
in $40 \mu \mathrm{l}$ aluminium pans. An identical empty pan was used as a reference. The samples were scanned at $5{ }^{\circ} \mathrm{C} / \mathrm{min}$ with a $20 \mathrm{ml} / \mathrm{min}$ nitrogen purge.

Moisture content, Sedimentation volume, Bulk \& tap density, Carr's Index, Hausner's ratio and Hydration capacity

Moisture content: One gram of accurately weighed sample was subjected to controlled heating at programmed temperature for $5 \mathrm{mins}$ (AND MS-70 moisture analyzer, Japan), the \% moisture loss from the sample gave an estimation of moisture content.

Sedimentation volume: Sedimentation volume or the volume of water taken up by gram of sample was determined using reported method (8). Precisely, $1 \mathrm{gm}$ of sample was accurately weighed and transfer to a $10 \mathrm{ml}$ measuring cylinder. The volume of cylinder was made up to $10 \mathrm{ml}$ using distilled water. After keeping it undisturbed for an hour, the liquid was decanted and the volume measured.

Bulk and Tap density: The procedure followed is also referred to as cylinder drop technique. Accurately weighed sample (10 gram) of each disintegrant was introduced into a $10 \mathrm{ml}$ graduated measuring cylinder. The volume occupied by the sample was measured following which the cylinder was subjected to 100 taps and the final volume change was noted down. Bulk density $\left(\rho_{\text {bulk }}\right)$ and Tap density $\left(\rho_{\text {tap }}\right)$ was calculated by dividing the weight of sample by volume of untapped and tapped powder respectively.

Carr's index and Hausner's ratio: The Carr's index and the Hausner's ratio were calculated using the equation $\left[\left(\rho_{\text {tap }}-\rho_{\text {bulk }}\right) / \rho_{\text {tap }}\right] \times 100$ and $\rho_{\text {tap }} / \rho_{\text {bulk, }}$, respectively (9-10).

Hydration capacity: The procedure utilized was as follows: $10 \mathrm{ml}$ of water was taken in a petridish and covered with a filter paper such that only the centre of paper touches the surface of water. The filter paper was then allowed to get soaked. The wet paper was then weighed and $100 \mathrm{mg}$ of sample was placed at the centre of the filter paper. It was kept undisturbed for 1 hour followed by reweighing of the paper. Hydration capacity was found out by difference in the weight of paper.

\section{Photo microscopic Studies}

Photo microscopic analysis was carried out on both dry and wet samples of disintegrants to study their swelling behavior. These studies were carried out using Kruss MBL 3100 Inverse microscope equipped with Canon Power Shot S80 digital camera.

\section{Preparation of Tablets}

Aceclofenac was used as a hydrophobic active in all tablet formulations. Different batches of tablets were prepared using either lactose (Pharmatose ${ }^{\circledR}$ $50 \mathrm{M}$ or $150 \mathrm{M})$ or Di-calcium phosphate (Emcompress ${ }^{\circledR}$ and DCL 11) as fillers; magnesium stearate as lubricant. Disintegrants (CLP, Ac-DiSol) were added to the formula at defined concentration ( $5 \% \mathrm{w} / \mathrm{w}$ of tablet weight). Tablets corresponding to $450 \mathrm{mg}$ total weight with $100 \mathrm{mg}$ of aceclofenac were prepared either by wet granulation or direct compression on $11 \mathrm{~mm}$ flat round punch on single stroke tablet press (CADMACH, India).

To study the effect of varying concentration and hardness on disintegration properties, tablets were prepared with different concentrations of disintegrant $(2-5 \% \mathrm{w} / \mathrm{w}$ of tablet weight $)$ and compressed at hardness ranging from $4-7 \mathrm{~kg} / \mathrm{cm}^{2}$ (measured using EXPO $^{\circledR}$ Tablet hardness tester EIC-66). Further, to establish a suitable mode of incorporation of the disintegrant, tablets with CLP $(5 \% \mathrm{w} / \mathrm{w}$ of the tablet weight) incorporated either intragranularly, extragranularly or in combined form were prepared and compressed at a hardness of $5 \mathrm{~kg} / \mathrm{cm}^{2}$.

\section{Evaluation of Tablets}

\section{Wetting studies}

Wetting studies were carried out according to the reported method (11). In brief, the set up for the study included a set of filter paper band supported on glass petridish filled with water. Tablets for study were placed at the centre of the paper, such that the water absorption occurs only from its lower surface. The time taken for water to reach the centre of the upper surface was noted as wetting time. The readings were taken as average of six observations.

\section{Disintegration studies}

The disintegration test was performed in water at 37 ${ }^{\circ} \mathrm{C}$ using a Tablet disintegration apparatus (Electrolab, India). The disintegration times reported are averages of six determinations. 


\section{Dissolution studies}

Tablets were also subjected to dissolution studies to evaluate the effect of disintegrant on drug dissolution. Dissolution test was carried out using USP XXIV Type II (paddle) apparatus at $37^{\circ} \mathrm{C}$; the paddles were rotated at $100 \mathrm{rpm}$. Dissolution medium was selected as $900 \mathrm{ml}$ (buffer $\mathrm{pH}$ 6.8) as aceclofenac shows maximum solubility in buffer pH 6.8 (12). Five milliliter aliquots were withdrawn at intervals of $5,10,15,30$ and 45 mins and replaced with $5 \mathrm{ml}$ of fresh medium. The samples were analyzed for aceclofenac content by UV spectroscopy at $275 \mathrm{~nm}$.

\section{Dwell time study}

To study the effect of compression time on disintegration property of disintegrant, dwell time study was performed. A 1:1 w/w mixture of CLP and DCP was compressed into a disc using $\mathrm{KBr}$ pellet press (Spectrolab, Model SL-89, Mika, Germany) at maximum pressure $\left(3000 \mathrm{lb} / \mathrm{in}^{2}\right)$. The disc was subjected to pressure for varying time period (1-5mins). The compressed discs were then evaluated for disintegration test.

\section{Toxicity studies}

The developed disintegrant was then evaluated for in vivo acute toxicity in rats. The animal requirement was approved by Institute's Animal Ethics Committee (IAEC) and all experiments were conducted as per the norms of Committee for the Purpose of Supervision of Experiments on Animals, India (CPCSEA, India). The test was carried out as per OECD 420 guideline for acute toxicity test using fixed dose procedure [FDP] (13). Male Holzman's rats weighing (250 gms approx.) were selected for study. Three groups of 6 rats each were starved for 24 hours and divided into control and test group. CLP $(2000 \mathrm{mg} / \mathrm{kg}$ body weight suspended in Milli Q water) was fed orally to test group and control group received normal Milli $Q$ water. The groups were observed for mortality over a period of 14 days.

\section{RESULTS}

\section{Optimization of cross linking procedure}

Chemical cross linking process used in this study can be used to obtain different kind of products (hydrogels, sponges, slugs or beads) $(4-7,14)$. In our study the cross linking reaction was optimized in order to get the desired product, the batches of experiments carried out are listed in (Table 1).

It was found that PVA: GA ratio of at least 1:1 $\mathrm{w} / \mathrm{w}$ or above was required to obtain the desired product. When the reaction was carried out at room temperature RT $\left(25{ }^{\circ} \mathrm{C}\right)$, the product obtained ranged from slugs to hydrogels, which didn't show any disintegrant activity. However, it was observed that by carrying out the reaction at $50-60{ }^{\circ} \mathrm{C}$, white amorphous precipitate was obtained which later showed a very good disintegrant property. Reaction occurred well in the presence of $0.2-0.1 \mathrm{~N} \mathrm{HCl}$ and 20-30 minutes duration (reaction time) was found to be optimum. Volume of acid also played a crucial role as at lower volume the process failed to give discrete precipitates rather it formed a gelled mass. The drying steps tried in this method included air drying, oven drying and freeze drying. It was seen that air drying resulted in a product with high residual moisture $(12 \% \mathrm{w} / \mathrm{w})$, which was ineffective in showing any disintegrant property. On the other hand both oven drying and freeze drying gave a completely dry product $(2.13 \pm 0.09$ $\% \mathrm{w} / \mathrm{w}$ and $2.02 \pm 0.03 \% \mathrm{w} / \mathrm{w}$ respectively) with good disintegrant property. It was seen that the freeze dried product was slightly better in terms of disintegrating property which could be attributed to increase in the porosity of the material. Thus, further studies for evaluation of disintegration properties were carried out with freeze dried product.

\section{Characterization studies}

Figure 1 shows the SEM images of the raw material and the dried crosslinked products. As seen from the figure, the crosslinked product displayed an amorphous and porous structure as compared to the more crystalline PVA particles. Product dried using freeze drying was found to have more porous and irregular surface as compared to oven dried product. 
Table 1. Optimization of cross linking reaction conditions (selected batches)

\begin{tabular}{|c|c|c|c|c|c|c|c|c|}
\hline FORMULA & $\begin{array}{l}\text { Batches } \\
\text { CLP I }\end{array}$ & CLP II & CLP III & CLP IV & CLP V & CLP VI & CLP VII & CLPVIII \\
\hline $\begin{array}{l}\text { PVA:GA } \\
\text { ratio }(\mathrm{w} / \mathrm{w})\end{array}$ & $1: 1.5$ & $1: 1.5$ & $1: 1.5$ & $1: 1.5$ & $1: 1.5$ & $1: 1.25$ & $1: 1$ & $1: 0.75$ \\
\hline $\begin{array}{l}\text { Acidic } \\
\text { conditions }\end{array}$ & $0.2 \mathrm{~N} \mathrm{HCl}$ & $0.2 \mathrm{~N} \mathrm{HCl}$ & $0.2 \mathrm{~N} \mathrm{HCl}$ & $0.2 \mathrm{~N} \mathrm{HCl}$ & $0.1 \mathrm{~N} \mathrm{HCl}$ & $0.1 \mathrm{~N} \mathrm{HCl}$ & $0.1 \mathrm{~N} \mathrm{HCl}$ & $0.1 \mathrm{~N} \mathrm{HCl}$ \\
\hline $\begin{array}{l}\text { Volume of } \\
\text { acid } \\
\text { (ml) }\end{array}$ & 150 & 250 & 250 & 250 & 250 & 250 & 250 & 250 \\
\hline $\begin{array}{l}\text { Duration of } \\
\text { reaction } \\
\text { (mins) }\end{array}$ & $5-10$ & $5-10$ & $5-10$ & $20-30$ & $20-30$ & $20-30$ & $20-30$ & $20-30$ \\
\hline Temperature & RT & RT & $50-60^{\circ} \mathrm{C}$ & $50-60^{\circ} \mathrm{C}$ & $50-60^{\circ} \mathrm{C}$ & $50-60^{\circ} \mathrm{C}$ & $50-60^{\circ} \mathrm{C}$ & $50-60^{\circ} \mathrm{C}$ \\
\hline
\end{tabular}

Average particle size of oven dried and freeze dried CLP was found to be $220.53 \pm 2.01 \mu \mathrm{m}$ and 119.76 $\pm 1.58 \mu \mathrm{m}$ respectively. Particle size analysis also gave an estimation of specific surface area (Table 2) which was seen to increase significantly in the product as compared to the raw material. Specific surface area was greater for freeze dried product.

Fourier-transform infrared (FT-IR) spectroscopy was utilized to confirm the crosslinking reaction. FTIR spectrum of pure PVA sample (Figure $2 \mathrm{~A}$ ) clearly reveals the major peaks associated with poly vinyl alcohol. For instance, $\mathrm{C}-$ $\mathrm{H}$ broad alkyl stretching band $\left(v=2850-3000 \mathrm{~cm}^{-1}\right)$ and typical strong hydroxyl bands for free alcohol (non bonded $-\mathrm{OH}$ stretching band at $v=3600-3650$ $\left.\mathrm{cm}^{-1}\right)$, and hydrogen bonded band $(v=3200-3570$ $\mathrm{cm}^{-1}$ ) (15). FTIR spectrum in Figure $2 \mathrm{~B}$ is associated with CLP (PVA cross linked by glutaraldehyde). It can be observed that two important peaks at $v=2870$ and $2720 \mathrm{~cm}^{-1}$ of $\mathrm{C}-\mathrm{H}$ stretching are related to aldehydes, a duplet absorption with peaks attributed to the alkyl chain (15-16). It was also seen that the O-H stretching vibration peak $\left(v=3330-3350 \mathrm{~cm}^{-1}\right)$ was decreased when compared to pure PVA. This result suggests that the hydrogen bonding becomes weaker in cross linked PVA compared to pure PVA because of the reduction in the number of $\mathrm{OH}$ groups due to acetal formation (2). It was observed that there was no major increase in the $\mathrm{C}=\mathrm{O}$ band at approximately $v$ $=1715 \mathrm{~cm}^{-1}$ indicating that the aldehyde groups of GA was almost completely used up in the cross linking reaction with $\mathrm{O}-\mathrm{H}$ groups of PVA chain. In addition, the C-O stretching at approximately 1100 $\mathrm{cm}^{-1}$ in pure PVA is replaced by a broader absorption band (from $v=980$ to $1110 \mathrm{~cm}^{-1}$ ), which can be attributed to the ether (C-O) and the acetal ring (C-O-C) bands formed by the cross linking reaction of PVA with GA (2). Thus, it was assumed that CLP was a crosslinked product of PVA, formed by chemical crosslinking of glutaraldehyde with PVA Figure 3 presents the XRD patterns of PVA and CLP (oven dried and freeze dried). The characteristic peaks of PVA at 19.71, 20 and 23.32 $\circ 2 \theta$ were absent in the diffractograms of CLP.

DSC thermograms of samples are showed in figure 4. As seen from the figure, PVA shows two characteristic peak at around 100-120 and 190-220 ${ }^{\circ} \mathrm{C}$. The peak at around $100-120{ }^{\circ} \mathrm{C}$ represents the evaporation of residual water present in the sample. The sharp peak at approximately $230{ }^{\circ} \mathrm{C}$ represents the melting of PVA. On comparing the DSC thermogram of CLP to PVA both these peaks were found to disappear. CLP was found to show a new peak at $80-90{ }^{\circ} \mathrm{C}$, which could be attributed to the softening point of the formed crosslinked product. 


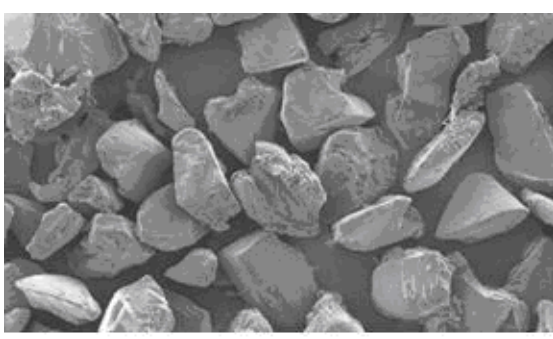

PVA (X100)

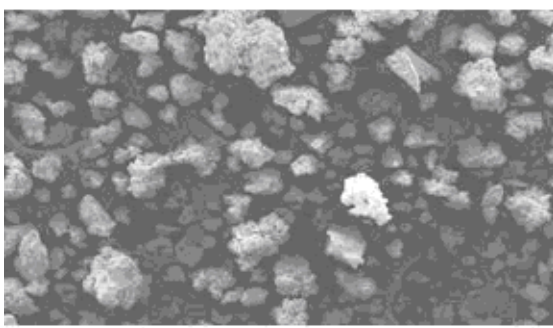

CLP oven dried $(\mathrm{X} 100)$

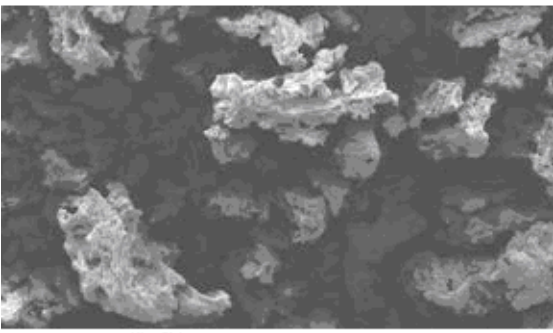

CLP freeze dried (X100)

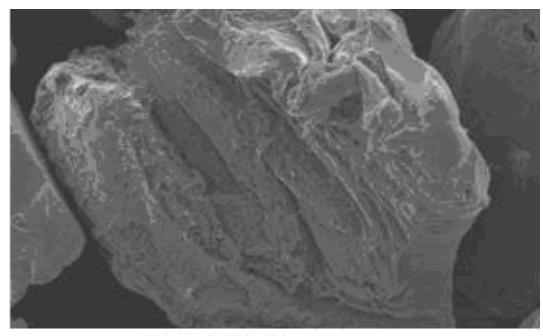

PVA (X500)

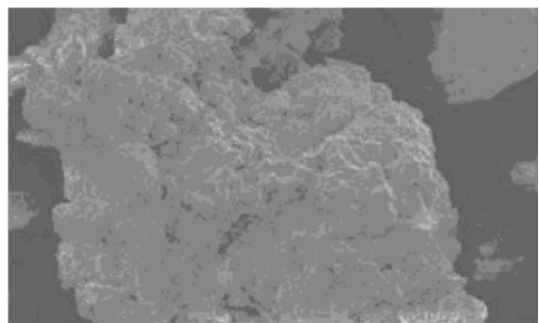

CLP oven dried $(\mathrm{X500})$

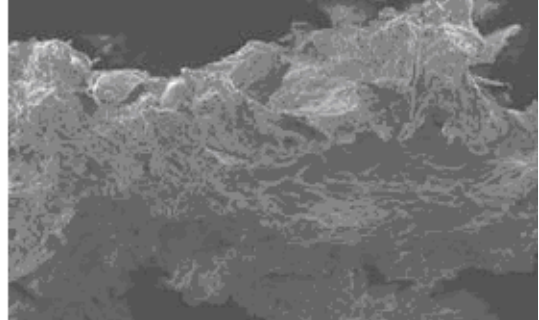

CLP freeze dried $(\mathrm{X} 500)$

Figure 1. SEM images of PVA, CLP oven dried and CLP freeze dried

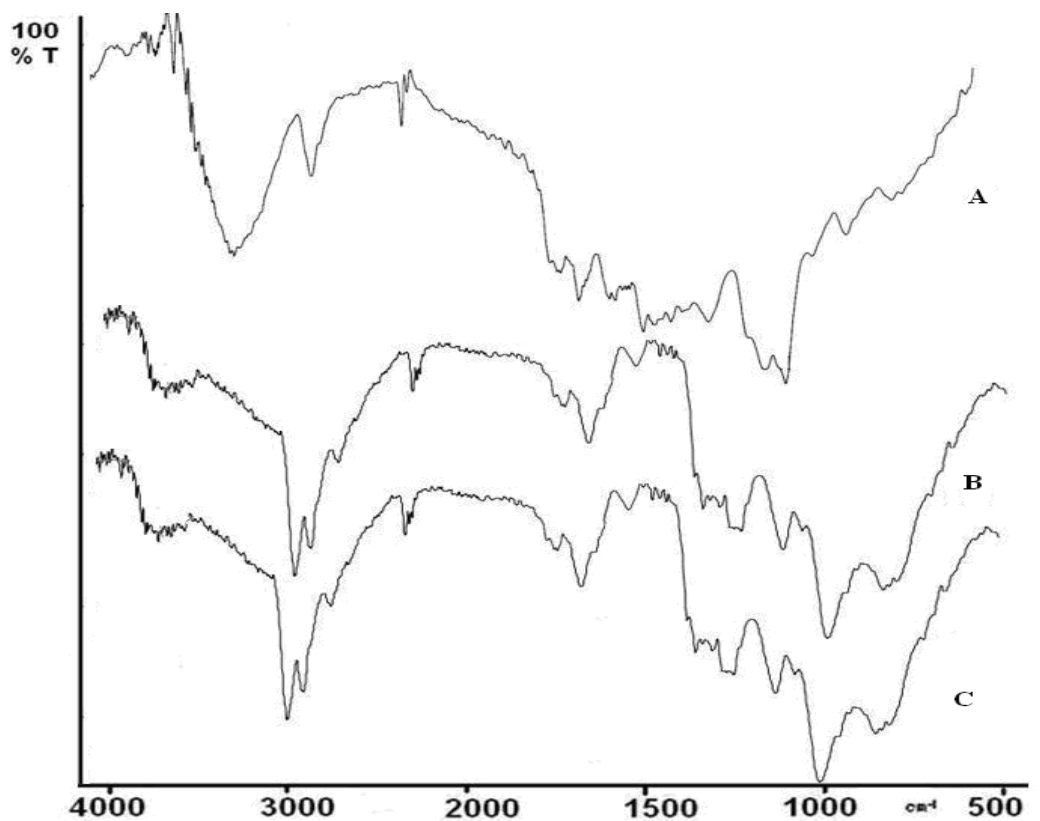

Figure 2. FTIR spectra of A] PVA and B] CLP freeze dried and C] CLP oven dried 


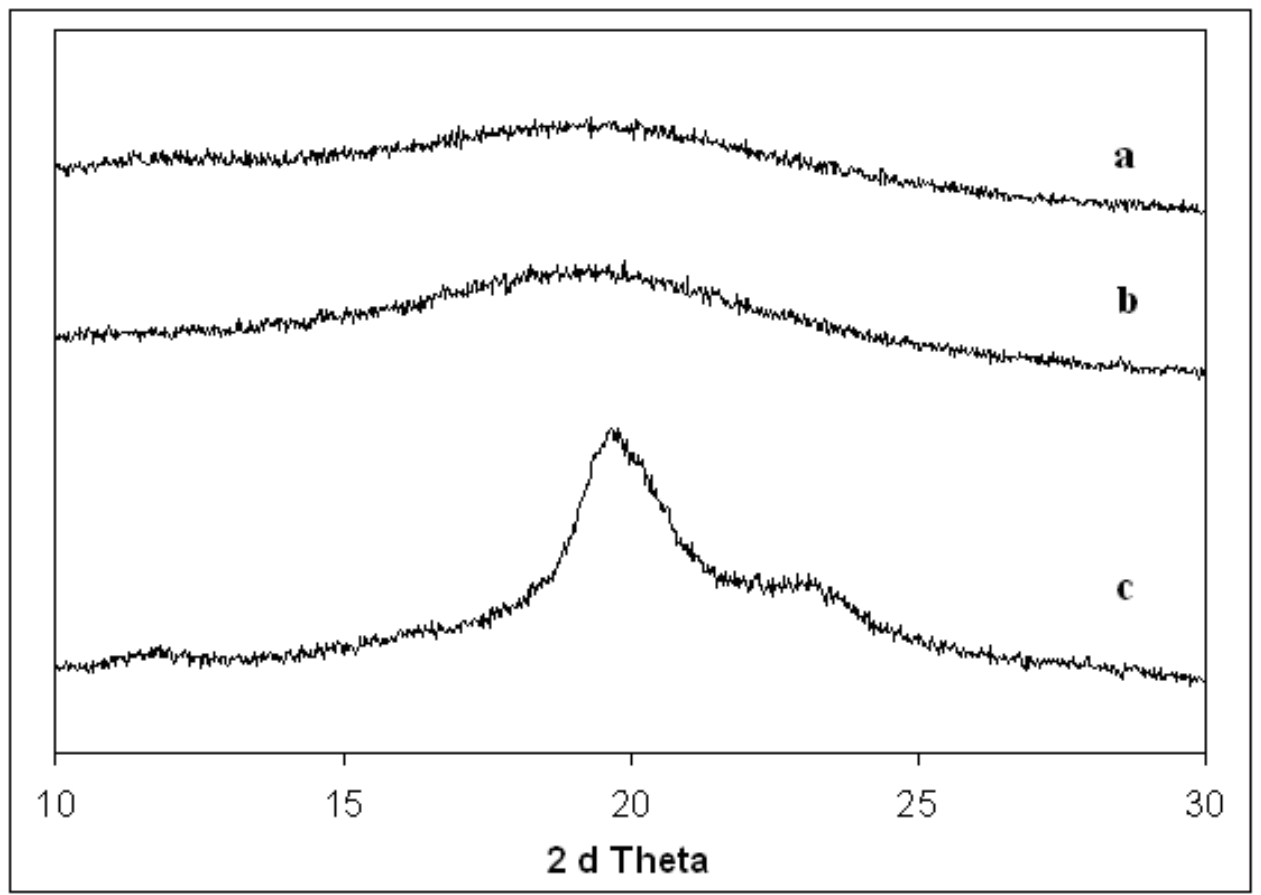

Figure 3. X-RD patterns of a] PVA; b] CLP oven dried and c] CLP Freeze dried

Table 2. Particle size and specific surface area of oven dried and freeze dried CLP.

\begin{tabular}{lcccccc}
\hline \multicolumn{1}{c}{ Parameters } & \multicolumn{2}{c}{ Oven dried CLP } & \multicolumn{3}{c}{ Freeze dried CLP } \\
& I & II & III & I & II & III \\
\hline $\begin{array}{l}\text { Particle size }(\mu \mathrm{m}) \\
\text { Mean } \pm \text { S.D }\end{array}$ & 222.4 & 218.1 & 220.8 & 118.4 & 119.4 & 121.5 \\
& & $220.53 \pm 2.01$ & & & $119.76 \pm 1.58$ & \\
$\begin{array}{l}\text { Specific surface } \\
\text { area }\left(\mathrm{m}^{2} / \mathrm{g}\right)\end{array}$ & 0.0314 & 0.0324 & 0.0301 & 0.481 & 0.486 & 0.457 \\
Mean \pm S.D & & & & & & \\
\end{tabular}

Figure 5 shows photomicroscopic slides of CLP, Ac-Di-Sol, SSG and crospovidone in both dry state and wet state. As seen from the results (Figure 5), CLP showed negligible swelling and discreteness of particles in wet state as compared to both Ac-Di-Sol and SSG. The results of this study are in good agreement with the sedimentation volume and hydration capacity studies.

\section{Evaluation of physical properties}

The developed product CLP (freeze dried) was subjected to evaluation test for physical properties and results of same were compared with that of AcDi-Sol, SSG ad crospovidone. Results obtained from the evaluation studies are given in Table 3. Hausner's ratio and the Carr index have been widely used to estimate the flow properties of powders. A Hausner's ratio of less than 1.20 is indicative of good flowability of the material, whereas a value of 1.5 or higher suggests a poor flow display by the material (17). The Carr index values of 5-10, 12-16, 18-21, and 23-28 indicate excellent, good, fair, and poor flow properties of the material, respectively (9). Thus from the obtained values of Hausner's ratio and the Carr index, it can be suggested that CLP posses excellent flow properties. 


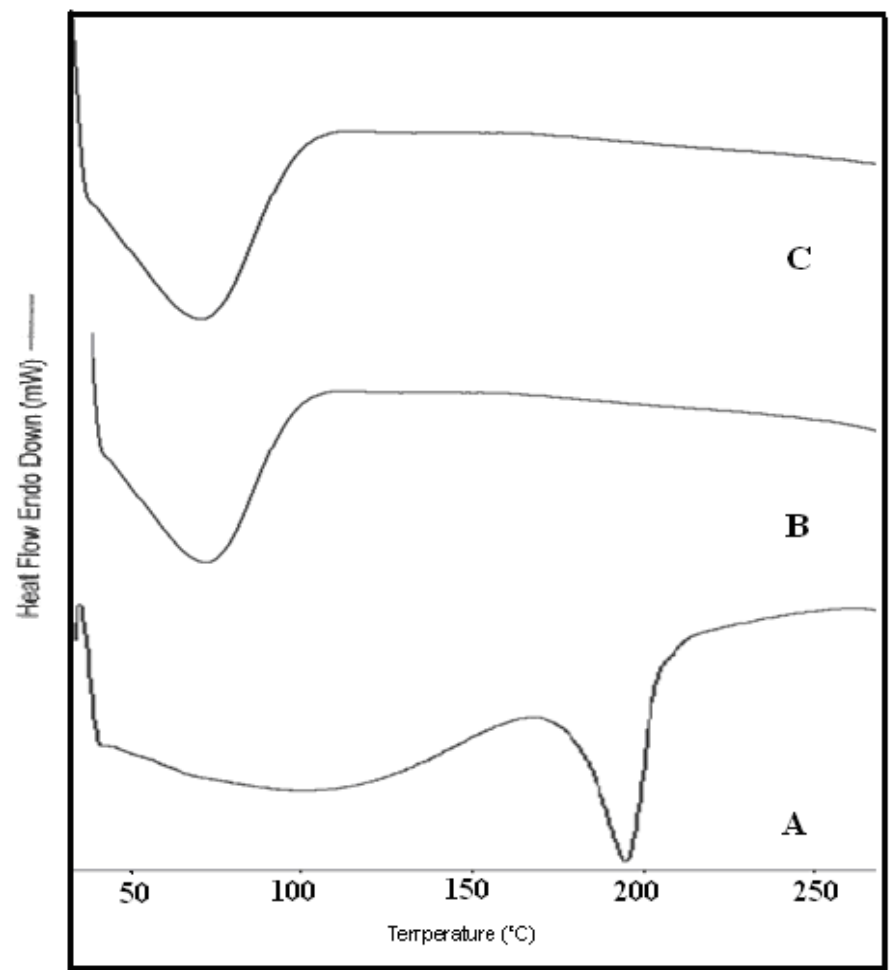

Figure 4. DSC thermo grams of A] PVA; B] CLP oven dried and C] CLP freeze dried

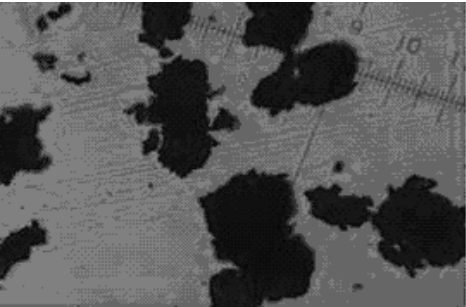

CLP (dry sample)

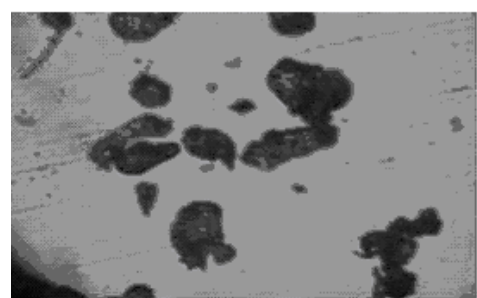

Ac- Di- Sol (dry sample)

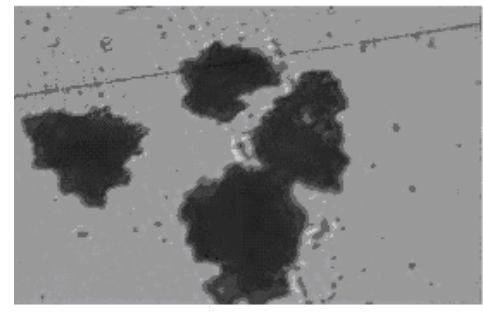

SSG (dry sample)

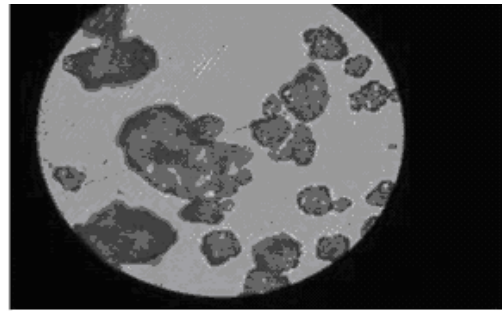

CLP (wet sample)

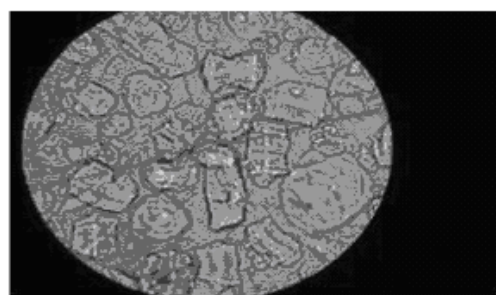

Ac- Di- Sol (wet sample)

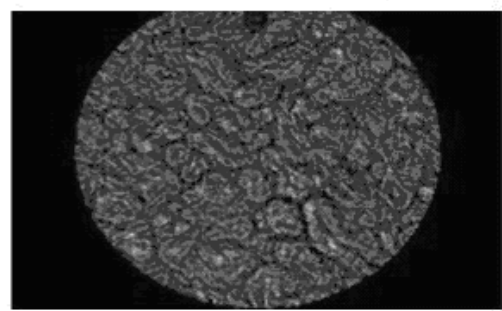

SSG (wet sample)

Figure 5. Photomicrographs of CLP, Ac-Di-Sol and SSG in both dry form and wet form 
Table 3. Comparative powder properties of disintegrants

\begin{tabular}{lllll}
\hline Properties & $\begin{array}{l}\text { CLP freeze dried } \\
\text { Mean (S.D.) }\end{array}$ & $\begin{array}{l}\text { Ac-Di-Sol } \\
\text { Mean (S.D.) }\end{array}$ & $\begin{array}{l}\text { SSG } \\
\text { Mean (S.D.) }\end{array}$ & $\begin{array}{l}\text { Crospovidone } \\
\text { Mean (S.D.) }\end{array}$ \\
\hline & & & & \\
Moisture content (\%w/w) & $1.13(0.09)$ & $2.627(0.12)$ & $11.214(0.158)$ & $8.011(0.052)$ \\
Sedimentation volume (ml/g) & $4.93(0.2516)$ & $20.16(1.2683)$ & $29.9(1.1532)$ & $18.2(1.0520)$ \\
Bulk density $(\mathrm{g} / \mathrm{ml})$ & $0.449(0.001)$ & $0.624(0.003)$ & $0.646(0.001)$ & $0.536(0.009)$ \\
Tap density $(\mathrm{g} / \mathrm{ml})$ & $0.502(0.001)$ & $0.834(0.002)$ & $0.957(0.002)$ & $0.665(0.003)$ \\
Carr's index & 10.61 & 25.14 & 32.42 & 19.39 \\
Hausner ratio & 1.12 & 1.34 & 1.48 & 1.24 \\
Hydration capacity (\%) & $1.58(0.010)$ & $7.32(0.016)$ & $9.10(0.09)$ & $5.43(0.11)$ \\
& & & & \\
\hline
\end{tabular}

\section{Disintegration properties}

Batches of experiments were conducted to evaluate the disintegration properties of CLP (freeze dried). Tablets with constant target weight $(450 \mathrm{mg})$ were prepared using various concentration of disintegrant at different hardness; other parameters were also varied in order to evaluate its disintegration property. Ac-Di-Sol is considered to be better in terms of performance as compared to SSG and Crospovidone (18) and in our preliminary study; tablets with Ac-Di-Sol gave the better results as compared to SSG and Crospovidone. Thus, tablets with Ac-Di-Sol at same concentrations as CLP were used as control for comparison purpose. Tablets prepared using wet granulation gave a better result as compared to direct compression and thus wet granulation was chosen as method of choice. It was observed that the disintegration property of CLP was unaffected by the type of filler used in the formulation as it gave similar disintegration time for tablets with either hydrophilic filler (Lactose) or hydrophobic filler (Di-calcium Phosphate). It was also observed that the mode of incorporation of disintegrant in the tablet showed a profound effect on the disintegration time (Table 4), extragranular addition proved to be ideal as it was seen that tablets with just intragranular addition or addition at both intra and extra granular level did not give a satisfactory result.

Figures 6-7 display the results of disintegration test and wetting studies. As seen from the figures, CLP appears to be an interesting disintegrant. The disintegrant was found to be effective at all concentration ranging from $2-5 \% \mathrm{w} / \mathrm{w}$. Further, it was also seen that tablet compressed at higher hardness took longer time to get wet. However, the disintegration time was surprisingly found to decrease with increase in the hardness.

\section{Dwell time study}

It was observed that the disintegration of the disc was affected with the time as the disintegration time was seen to decrease with the increase in the exposure time of compression pressure (Figure 8). The reason for this observation can be attributed to the fact that when the compression pressure is applied to the particles they undergo plastic deformation which is a time dependent process. Thus, increasing the exposure time leads to proportional increase in the plastic deformation of particles (19).

\section{In vitro dissolution}

To ascertain the overall acceptability of a disintegrant, it must be shown that no interference with the dissolution behavior of drug from the tablet is involved (20). Ac-Di-Sol is known to disintegrate the tablet into fine particles and consequently results in an increase in the drug release. To investigate the effect of CLP (freeze dried) on drug release, tablets without any disintegrants and with CLP and Ac-Di-Sol $(5 \% \mathrm{w} / \mathrm{w})$ were subjected to invitro dissolution studies. Figure 9 shows the comparative release profile of tablets. As seen from the figure, the release of drug was enhanced as compared to tablet without any disintegrant and tablets with CLP and Ac-Di-Sol gave almost similar release profiles. Thus it can be claimed that the disintegration mechanism of CLP results in generation of fine particles with enhanced exposed area for medium interaction as is seen with Ac-DiSol. 
Table 4. Effect of mode of incorporation of disintegrant on wetting time and disintegration time

\begin{tabular}{lccc}
\hline Mode of Incorporation & Total Disintegrant added $(\%$ w/w) & Wetting time $(\mathrm{sec})$ & Disintegration Time $(\mathrm{sec})$ \\
\hline Extragranular only & 2 & $118.6 \pm 1.8$ & $123.9 \pm 1.7$ \\
& 3 & $40.70 \pm 1.4$ & $42.30 \pm 1.6$ \\
& 4 & $31.70 \pm 0.3$ & $33.20 \pm 0.4$ \\
Intra \& Extra granular & 5 & $21.90 \pm 0.1$ & $26.20 \pm 0.2$ \\
& 2 & $227.3 \pm 2.2$ & $248.2 \pm 2.8$ \\
& 3 & $137.4 \pm 2.2$ & $138.4 \pm 2.1$ \\
Intra granular only & 4 & $109.4 \pm 0.5$ & $117.2 \pm 1.8$ \\
& 5 & $97.80 \pm 0.8$ & $356.2 \pm 2.2$ \\
& 2 & $348.9 \pm 3.2$ & $294.5 \pm 3.2$ \\
& 3 & $256.7 \pm 2.7$ & $247.3 \pm 4.7$ \\
\hline
\end{tabular}

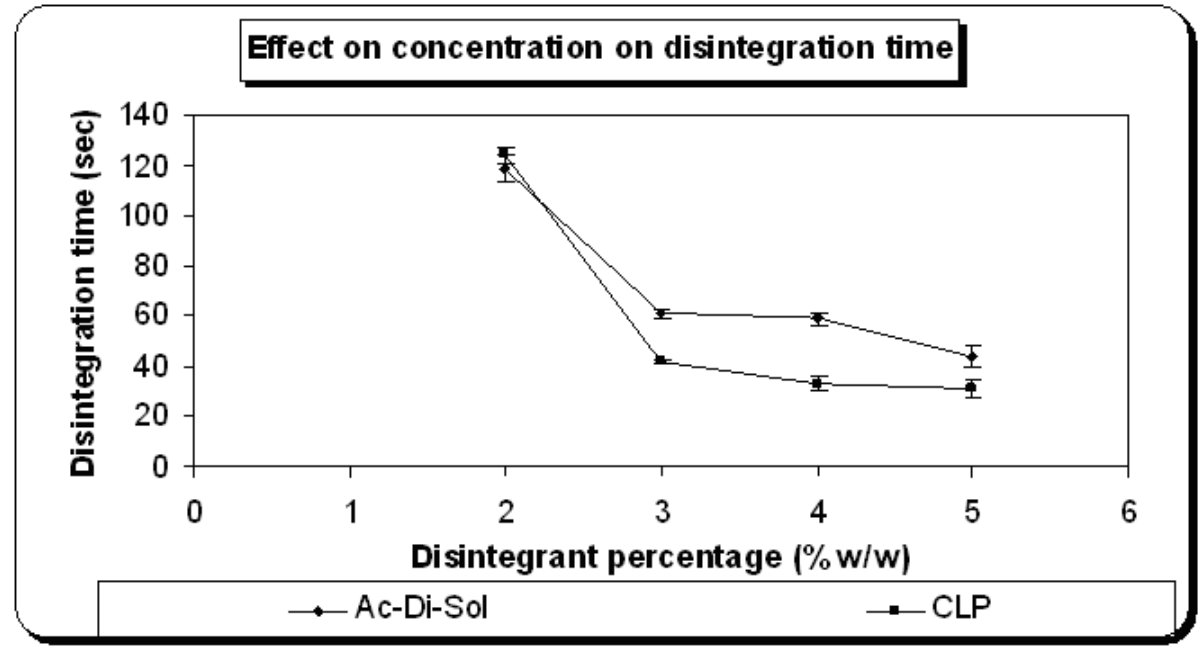

Figure 6a. Disintegration test for tablets containing different percentages of disintegrates compressed at hardness of 5 $\mathrm{kg} / \mathrm{cm}^{2}$

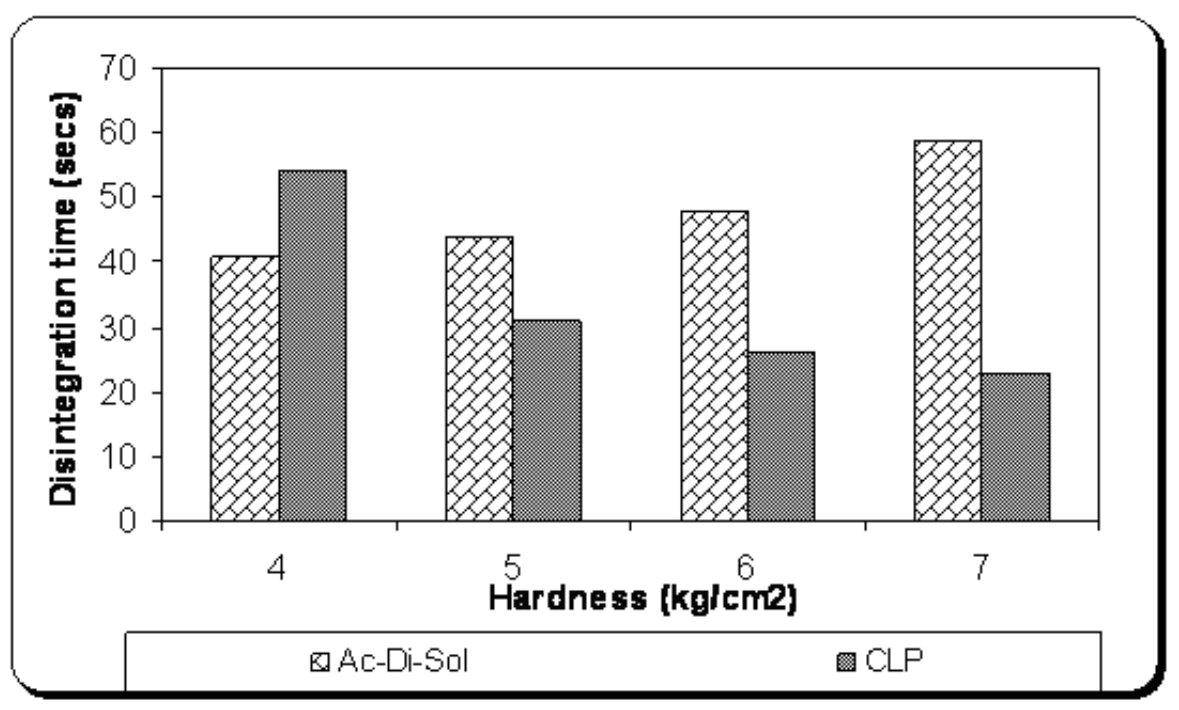

Figure 6b. Effect of hardness on disintegration time of tablets with disintegrants $(5 \% \mathrm{w} / \mathrm{w})$ 


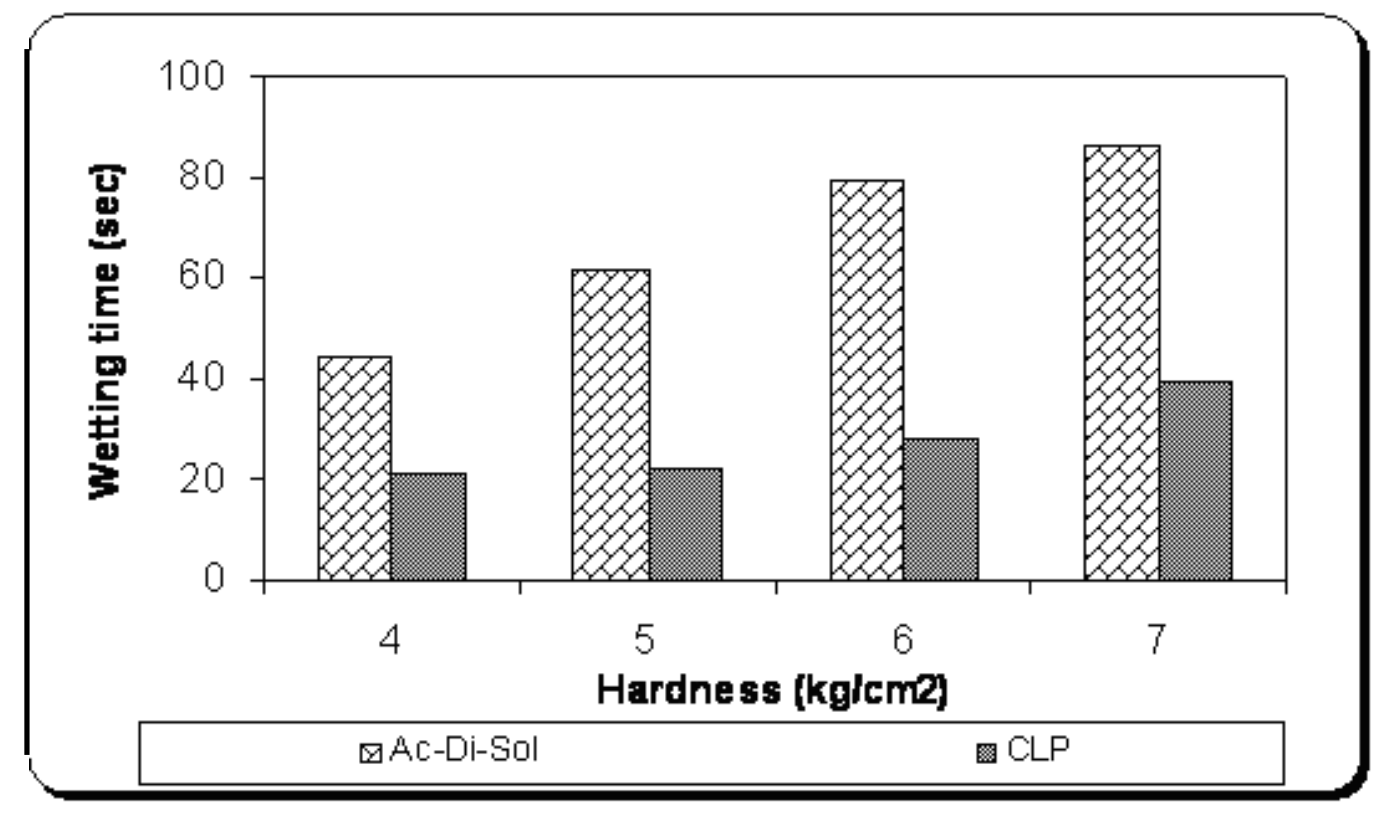

Figure 7a. Wetting test for tablets containing different percentages of disintegrants compressed at hardness of $5 \mathrm{~kg} / \mathrm{cm}^{2}$

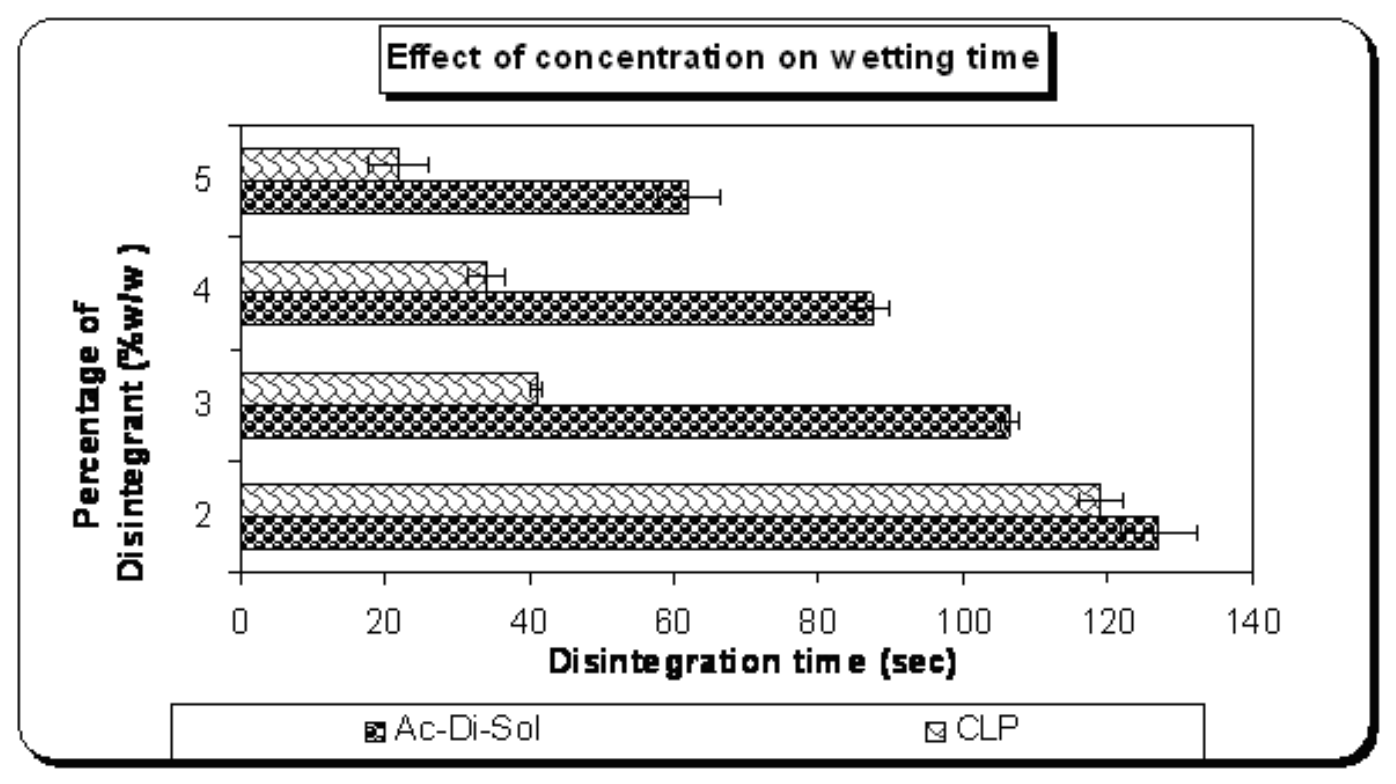

Figure 7b. Effect of hardness on wetting time of tablets with disintegrants $(5 \% \mathrm{w} / \mathrm{w})$

In-vivo toxicity

At the end of 14 days, a $100 \%$ survival without any evident toxicity was observed. Thus, it can be assumed that the oral LD50 is likely to be above
$2000 \mathrm{mg} / \mathrm{kg}$ body weight and therefore the developed disintegrant (CLP) can be considered as safe for oral use (13). 


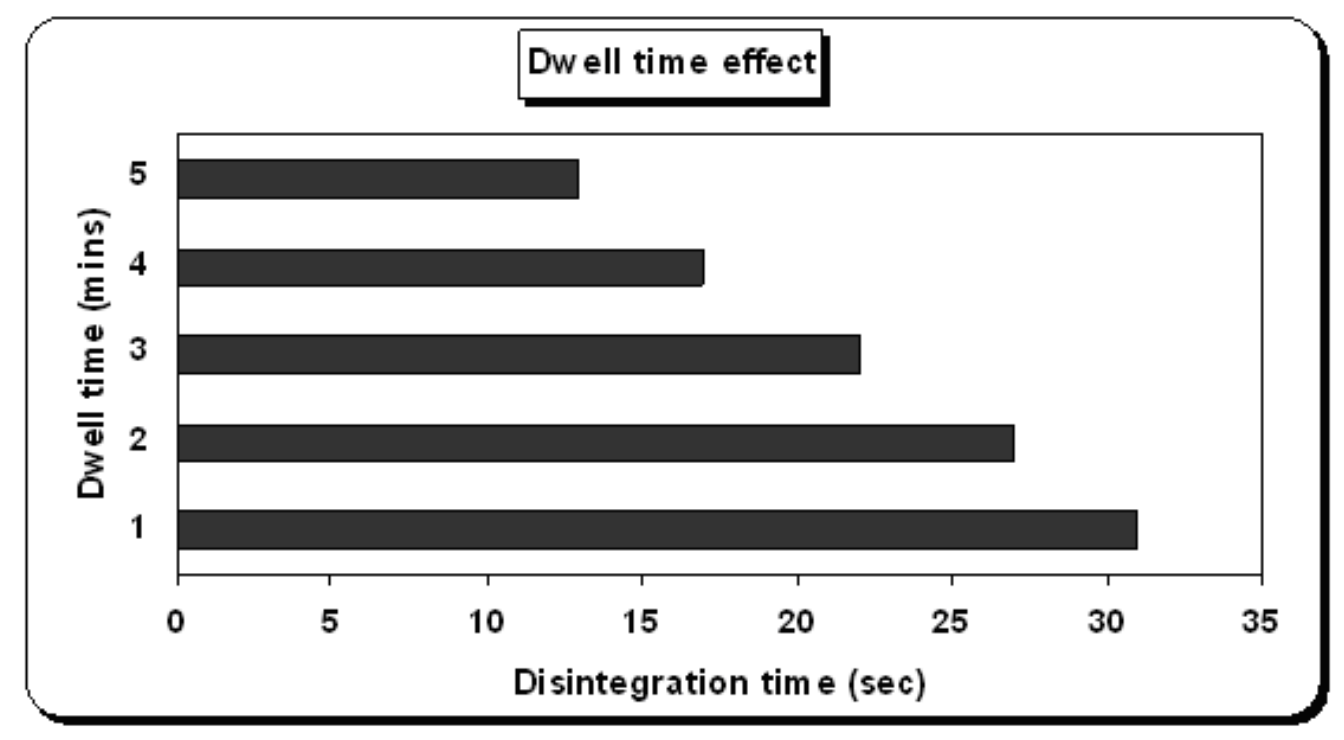

Figure 8. Effect of dwell time on disintegration behavior

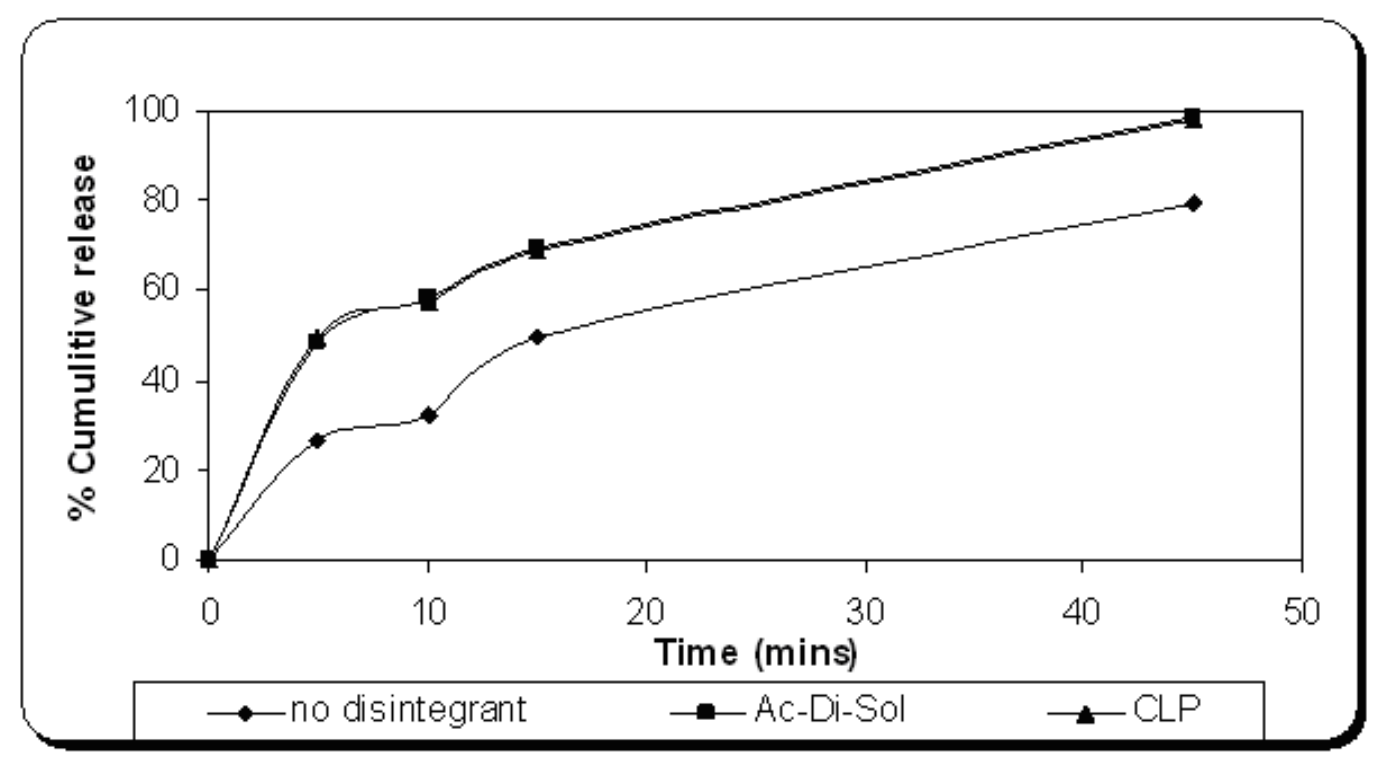

Figure 9. Drug release profile of tablets without disintegrant and with CLP and Ac-Di-Sol (5\% w/w)

\section{DISCUSSION}

It could be suggested that the process used in the current work resulted in formation of a crosslinked product with high hydrophobicity and good flow and excellent disintegration property. The crosslinking of PVA by glutaraldehyde was confirmed from the detailed interpretation of FT-IR 
spectra as discussed in the results section. The change in the physical form of prepared substance was confirmed by the data obtained from DSC, XRD and SEM studies.

Also, it can be seen from figure 3 that the mode of drying had no effect on the XRD patterns as both oven dried and freeze dried product showed similar diffraction pattern. The disappearance of characteristic peaks and flatter diffractograms of CLP can be attributed to the amorphous nature of crosslinked product.

Owing to its porous structure CLP was found to show low bulk and tap density (Table 3). Also, the porous structure of formed product was prominent from the SEM images (Figure 1). The low \% moisture content could be attributed to relatively hydrophobic nature of CLP, resulting in lower residual moisture. The lower value for sedimentation volume and hydration capacity also suggests the limited swelling potential of CLP as compared to Ac-Di-Sol, SSG and Crospovidone. Moreover, Hausner's ratio \& Carr's index value of 1.12 and 10.61 (Table 3) suggested excellent flowability of the formed disntegrant.

An attempt was made to postulate the mode of action responsible for the disintegrating property of CLP. Results form the physical evaluation studies (lower values of hydration capacity and sedimentation volume) suggested an absence of swelling of CLP. Moreover, photomicroscopic studies (Figure 5) further confirmed that the developed disintegrant did not show any profound swelling and thus it can be stated that the disintegrating property of CLP was due some other mechanism. Results from wetting studies (Figure 7a and $7 b$ ), showed that CLP promoted wetting of the tablet suggesting that wicking is one of the predominant mechanisms responsible for the disintegration activity. The large specific surface area and porous morphology further ascertains wicking potentials of the developed disintegrant.

Further, it was seen that inclusion of water soluble filler resulted in an increase in the wetting time which was quite obvious as it could be attributed to the absorption of water by hydrophilic filler thereby leading to an alteration in channel for water uptake (21). However, it was seen that the presence of hydrophilic filler had no effect on disintegration. Moreover, it was also seen that tablets compressed at higher pressure resulted in faster disintegration. It is well known that wicking action is dependent on the porosity of the tablet which in turn is inversely proportional to the hardness of the tablet, thus the increase in hardness results in less porous tablets which in turn limits the wicking action (22). But in our case the disintegration time was not affected by the increased hardness. Thus, it was concluded that wicking alone was not responsible for the disintegrating property.

At this point, the decrease in the disintegration time at higher hardness was assumed as a justification for mechanical phenomenon of particle deformation. It is well known that at higher compression force the deformation of particles can display a greater disruptive force upon contact with the penetrating liquid resulting in faster disintegration (23). In fact, it has already been demonstrated that deformation of starch grains is one mode by which starch affects the disintegration (24). Thus, we can assume that particle deformation/reformation is also responsible for the disintegration effect. Results from dwell time (Figure 8) study further supports our above claim as particle deformation or plastic deformation is a time dependent process and it can be assumed that the greater deformation would lead to an equivalently quicker reformation leading to faster rupture of compressed mass. Thus, it was postulated that the mechanism of disintegration in this case consequently appears to be governed by wicking action and mechanical phenomenon i.e. deformation of disintegrant particles.

\section{CONCLUSION}

The developed excipient CLP was found to have excellent disintegration properties comparable to known disintegrant (Ac-Di-Sol). The disintegrant was found to be effective at a concentration ranging from $2-5 \% \mathrm{w} / \mathrm{w}$ and it also showed no untoward effect on drug dissolution. The mechanism of disintegrant was postulated as the one govern by wicking action and mechanical phenomenon of particle deformation. In vivo toxicity studies proved that the developed disintegrant is orally safe. In conclusion, the results provided here suggest that CLP has the potential to be used as an effective disintegrating agent. 


\section{ACKNOWLEDGEMENTS}

Authors are thankful to UGC India for providing financial assistance through senior research fellowship. Authors also wish to thank AICTE for providing grant for upgrading lab facility.

\section{REFERENCES}

1. Augsburger LL, Brzecko AW, Shah U, Hahm HA. Characterization and functionality of super disintegrants. In: Swarbrick, J.; Boylan, J.C., (Eds.), Encyclopedia of Pharmaceutical Technology, Marcel Dekker Inc., New York, pp. 269-291, 2000.

2. Lavin E, Snelgrove L. Vinyl polymers. In: Othmer, K., (Ed.), Encyclopedia of Chemical Technology, John Wiley, New York, pp 808-821, 1983.

3. Mack EJ, Okano T, Kim SW. In: N.A. Peppas (Ed.), Hydrogels in medicine and pharmacy, CRC Press, Boca Raton, USA, pp 65-72, 1988.

4. Kerber CW, Bank W, Horton JA. Polyvinyl alcohol foam: Prepackaged emboli for therapeutic embolization. Am. J. Roentgenol., 130:1193-1194, 1978.

5. Hassan CM, Peppas NA. Structure and applications of Poly (vinyl alcohol) hydrogels produced by conventional crossliking or by freezing/thawing method. Adv. Polym. Sci., 153: 37-65, 2000.

6. Bourke SL, Al-Khalili M, Briggs T, Michniak BB, Kohn J, Laura A, Warren P. A photo-crosslinked poly (vinyl alcohol) hydrogel growth factor release vehicle for wound healing applications. AAPS Pharm. Sci., 5: E33-E38, 2003.

7. Pillay V, Sibanda W, Danckwerts MP. Sequential design of a novel PVA-based crosslinked ethylenic homopolymer for extended drug delivery. Int. J. Pharm., 301: 89-101, 2005.

8. Rudnic EM, Kanig JL, Rhode CT. Effect of molecular structure variation on the disintegrant action of sodium starch glycolate. J. Pharm. Sci., 74: $647-650,1985$.

9. Carr RL. Classifying flow properties of solids. Chem. Eng., 72: 69-72, 1965.

10. Hausner HH. Friction conditions in a mass of metal powder. Int. J. Powder Metall., 3: 7-13, 1967.

11. Gohel MC, Patel SD, Shah NK, Jani GK. Evaluation of synthesized crosslinked tragacanth as potential disintegrant. Ind. J. Pharm. Sci., 59:113-118, 1997.
12. Mutalik S, Naha A, Usha AN, Ranjith AK, Musmade P, Manoj K, Anju P, Prasanna S. Preparation, in vitro, preclinical and clinical evaluations of once daily sustained release tablets of aceclofenac. Arch. Pharm. Res., 30: 222-234, 2007.

13. OECD Guidelines for the Testing of Chemicals, OECD 420. Acute Oral Toxicity—Fixed Dose Procedure. Organization for Economic Cooperation and Development, Paris. 2001.

14. Peppas NA. Hydrogels of poly (vinyl alcohol) and its copolymers. In: Peppas N.A. (Ed.), Hydrogels in medicine and pharmacy, CRC Press, Florida, pp. 148.1986.

15. Reisa EF, Camposa FS, Lagea AP, Leitea RC, Heneineb LG, Vasconcelosc WL, Lobatoa ZP, Mansurc HSSynthesis and characterization of poly (vinyl alcohol) hydrogels and hybrids for rMPB70 protein adsorption. Mater. Res., 9:185-191, 2006.

16. Mansur HS, Mansur AP. Small angle X-ray scattering, FTIR and SEM characterization of nanostructured PVA/TEOS hybrids by chemical crosslinking. Mater. Res. Soc. Symp. Proc., 873E (K1.9.1): 20-25, 2005.

17. Wells JI. Powder flow properties. In: Horwood, E. (Ed.), Pharmaceutical preformulation: The physicochemical properties of drug substances. John Wiley \& Sons, New York, pp. 1-15,1988.

18. Gordon MS, Rudraraju VS, Kaushik D, Chhowhan ZT. Effect of mode of superdisintegrant incorporation on dissolution in wet granulated tablets. J. Pharm. Sci., 82: 220-226, 1993.

19. Rees JE, Rue PJ. Time dependent deformation of some direct compression excipients. J. Pharm. Pharmacol., 30: 601-607, 1978.

20. Kornblum SS, Stoopak SB. A new tablet disintegrating agent: Cross-linked poly vinyl pyrollidone. J. Pharm. Sci., 62: 43-49, 1973.

21. Lowenthal W. Disintegration of tablets. J. Pharm. Sci., 61:1695-1711, 1972a.

22. Tanabe H, Otsuka K, Otsuka M. Theoretical Analysis of Tablet Hardness Prediction Using Chemo-informetric Near-Infrared Spectroscopy. Anal. Sci., 23: 857-862, 2007.

23. Botzolakis JE, Augsburger LL. Disintegrating agents in hard gelatin capsules Part I: Mechanism of action. Drug Dev. Ind. Pharm., 14: 29-41, 1988.

24. Lowenthal W. Mechanism of action of starch as a tablet disintegrant V: Effect of starch grain deformation. J. Pharm. Sci., 61: 455-460, 1972b. 